\title{
Accounting
}

\section{Quick response strategy under the financial constraint}

\author{
Jinpyo Lee $\mathrm{a}^{*}$
}

${ }^{a}$ College of Business Administration, Hongik University, Seoul, South Korea

\begin{tabular}{l}
\hline C H R O N I C L E \\
\hline Article history: \\
Received November 282019 \\
Received in revised format \\
December 262019 \\
Accepted January 282020 \\
Available online \\
February 2 2020 \\
\hline Keywords: \\
Bank credit \\
Financially constrained supply \\
chain \\
Newsvendor \\
Quick response \\
Stackelberg game
\end{tabular}
\begin{abstract}
A B S T R A C T
The major challenge, which the financially insufficient firm tries to overcome, is the uncertain demand during the sales season and the possible bankruptcy due to the lower demand than the initial order quantity. Most traditional studies on the operational decision problem address this challenge by assuming that the retailer has enough capital to procure as many products as necessary. However, small and medium size firms with insufficient capital or even startup companies are generally financially constrained for procuring or producing the product. Thus, to address the financially constrained problem, in this study we model a financially constrained two-level supply chain consisting of a financially-deficient retailer and a bank. In this supply chain, the supplier can sell a product at two wholesale prices to the retailer before and during the sales season, respectively. Then the retailer makes an initial order to the supplier with this loan from the bank and then sells the product to its customers at a selling price during the sales season. Moreover, if the realized demand is more than the initial order quantity, the retailer can make the second order at a higher wholesale price than the initial wholesale price. The analytical results from this model can be summarized as follows: First, the retailer's optimal initial ordering decision is a non-increasing function of the bank's decision, interest rate. Second, as the procuring cost through the quick response increases, the retailer's initial ordering quantity increases and thus the amount of loan from the bank increases. Third, as the retailer's initial capital increases, the amount of loan from the bank decreases. Forth, the retailer's initial ordering quantity with the quick response strategy is almost surely less than without the quick response strategy.
\end{abstract}

\section{Introduction}

A financial insufficiency has been a problem faced by the firm procuring the product before realizing the demand during the sales season. The major challenge, which the financially insufficient firm tries to overcome, are the uncertain demand during the sales season and the possible bankruptcy due to the lower demand than the initial order quantity. Most of the traditional studies in operations management have ignored the financial states of players in the supply chain or value chain, which result in infeasible or unrealistic practices or even catastrophic losses (Buzacott \& Zhang, 2004). A firm under an uncertain demand needs to manage inventory effectively through so called safety inventory which makes cushion against variation from the expected demand. Typically, the inventory cost and its financing cost are considered to be almost the same as or even more than an order processing cost (Kahneman \& Tversky, 2013). Most traditional studies on the operational decision problem assume that the retailer has enough working capital to procure as many products as necessary (Camerer, 1988). However, this can be

* Corresponding author.

E-mail address: jinpyo.lee@hongik.ac.kr (J. Lee) 
possible only for large firms with a financial strength. However, small and medium size firms with insufficient capital budget or even startup companies are generally financially-constrained for procuring or producing the product. The firm making an operational decision generally and frequently faces budget-deficient problem and thus financing the firm is widely used by the commercial bank, which helps diversifying its own portfolio and also improves the supply chain more efficiently. Generally, bank and bond market are the main source for financing the financially-constrained firms in the supply chain to process their own business, especially operational decision. However, small or startup companies have difficulty issuing bond in the commercial bond market due to risks such as the lack of credit history or even low creditworthiness.

In this study, we construct a financially constrained two-level supply chain consisting of a financially-deficient retailer and a bank. In this supply chain system, the supplier sells a product at two wholesale prices to the retailer before and during the sales season. Then the retailer makes an initial order to the supplier with this loan from the bank and then sells the product to its customers at a selling price during the sales season. Also, if the demand is more than the initial order quantity, the retailer can make the second order at the higher wholesale price than the initial wholesale price. We study a non-cooperative model in which bank and retailer in this supply chain try to optimize their own expected profits in the existence of a bank credit. In particular, a Stackelberg competition model is considered where the bank as the leader offers an interest rate and then the retailer as the follower decides how much money to borrow for the initial order quantity decision. Our model can be summarized as follows. First, we assume that the retailer is financially constrained so that she/he tries to use the outer financing sources which is the bank loan. Second, we consider the interaction between the bank and the financially-constrained retailer. Third, we consider the quick response contract between the supplier and retailer.

This paper is organized as following. Section 2 provides the literature review. Section 3 describes our model and discusses the equilibrium for a retailer and bank. Section 4 provides a numerical analysis, which shows the impact of the bank's interest rate and retailer's quick response strategy on the performance of a financially-constrained supply chain model, especially the bank's and retailer's optimal decision. Section 5 concludes the paper.

\section{Literature Review}

Traditionally, researches in the supply chain management focus on the optimization of the operational decision for the expected profit or loss and movement of products in the supply chain without financial constraint. However, the research considering the financial constraint in the supply chain and the quick response strategy between the retailer and the supplier attracts attention. So, we review various literatures focusing on financially constraint in the supply chain and the quick response strategy modelled in the operational decision. There have been some literatures related to the operational/productional decision with financial constraints. Lee and Rhee (2011) analyze and provide a trade-credit by a supplier as a tool for a supply chain coordination by assuming firms are financially constrained for inventory. Buzacott and Zhang (2004) and Xu and Birge (2004) analyze the decision-making process for a bank and a retailer using a newsvendor model, where the retailer is financially constrained for inventory. Buzacott and Zhang (2004) model a Stackelberg game between a bank(leader) and retailer(follower) where the retailer is financially constrained for inventory. Xu and Birge (2004) use periodically updated cash flow during the operational activities as a function of assets and liabilities. Dada and $\mathrm{Hu}$ (2008) analyze a supply chain system with a supplier, a financially constrained retailer and a bank where either a bank or a supplier can provide a credit to the retailer, and then provide a condition in which either credit from a bank or a supplier is preferred by the retailer. Jing et al. (2012) analyze a channel consisting of one supplier and one financially constrained retailer, where the retailer funds its operation by borrowing credit either from a bank market or from the supplier willing to lend. When only either bank or trade credit by supplier is viable, Jing et al. (2012) show that the trade credit by the supplier usually charges a high wholesale price and therefore would be less attractive than the credit by the bank for the retailer. Kouvelis and Zhao $(2012,2015)$ consider a supply chain consisting of single retailer and single supplier, where both the retailer and supplier are financially constrained. Kouvelis and Zhao (2012) show that a supplier should always provide credit to the retailer at lower rates than the risk-free rate and that the retailer, if offered an optimal trade credit contract, will always prefer the credit by the supplier to by bank. Kouvelis and Zhao (2015) provide results supporting the use of revenue-sharing contracts for financially constrained supply chains with bankruptcy risks. Using a model capturing the interaction among firms' operations decisions, the credit from the bank and trade credit from the retailer, Yang and Birge (2018) show that trade credit can achieve risk sharing and hence improve supply chain efficiency, and also illustrate that offering trade credit enables the retailer to obtain a higher profit if the retailer's own capital exceeds a threshold.

As shown above, in most of the previous literature relating to the financing supply chain, the retailer has single chance to make operational decision. However, some literatures point out that not all decision makers make single operational decision. Moreover, they mentioned that the second operational decision chance may increase the revenue and moreover reduce the mismatch cost during the sales season. So, the retailer's adoption of a quick response strategy with reactive capacity from the supplier can make profit generating chance by committing to partial procurement before the realization of demand but then still opting the additional second procurement just after observing the demand (Cachon \& Terwiesch, 2008). Iyer and Bergen (1997) 
study how a channel between supplier and financially sufficient retailer impacts choices of production and marketing variables under the quick response, building models of the operational decisions of supplier and retailers both before and after applying the quick response. Iyer and Bergen (1997) suggest strategic actions such as service level, wholesale price and ordering contract used to make the quick response profitable for both supplier and retailer. Suri (1998) introduce a quick response as an expansion of time-based competition, aimed at a single target with the goal of reducing lead times and provide a guideline for establishing a quick response strategy. Cachon and Swinney (2009) analyze the impact of quick response by the financially sufficient retailer on strategic consumer behavior and show that the existence of strategic consumers would reinforce the firm's adoption of quick response reducing the likelihood of deep discounts, which leads strategic consumers making purchasing decision at the regular price. Cachon and Swinney (2011) consider a quick response model for financially sufficient retailer and compare its performance to quick response system, enhanced design system and traditional system without enhanced design and quick response. Cachon and Terwiesch (2008) find that enhanced system can offer consumers a product at the point when they value more, making them less willing to wait for a clearance sale and experience a stockout. As shown in the literature review, a systematic operational management model that considers a financially constrained supply chain and the quick response strategy adopted by the retailer is important. However, there are no comprehensive models that address multiple operations-management issues together, especially regarding players' operational decisions, supply-chain financing, and quick response strategy. Hence, the new model presented in this paper will bridge a research gap in operations management, supply-chain financing, and quick response strategy.

\section{Method}

The sequence of our model is as follows. At time 0 , the retailer has initial capital budget $C_{0}$ and makes $Q$ amount of order at the unit cost $c$ from the supplier before knowing the actual demand in the sales season but knowing the distribution for the demand $D$ given by $F(x)=\operatorname{Pr}(D \leq x)=1-\bar{F}(x)$ and $f(x)=F^{\prime}(x)$. So, the retailer needs to pay for $c Q$ amount of money to the supplier and borrows $L=\left[c Q-C_{0}\right]^{+}$amount of money from the bank at the interest rate $r$. So, the bank and retailer conduct a Stackelberg Competition Game in which the bank(he) is a leader deciding the interest rate $r$ and the retailer(she) is a follower deciding the initial order quantity $Q$ before the sales season. More detail will be addressed in the following subsections.

\subsection{Notations}

\section{Decision Variables:}

$r$ : Bank's interest rate

$Q$ : Retailer's initial order quantity before the sales season

\section{Parameters:}

$c$ : Initial unit cost from the supplier before the sales season

$c^{\prime}$ : Unit cost from the supplier through Quick response contract during the sales season $c^{\prime}>c$

$s$ : Unit salvage cost after the sales season $c>s$

$p$ : Unit selling price during the sales season $p>c^{\prime}$

$D$ : Demand from consumers. $f(D)$ and $F(D)=1-\bar{F}(D)$ are the probability density function (pdf) and cumulative distribution function (cdf), respectively

$C_{0}$ : Retailer's initial capital

$C F_{t}$ : Cash flow at time $t . t=0$ is time before the sales season, $t=T$ is time after the sales season

$L$ : Amount of money which the retailer borrows from the bank. $L=c Q-C_{0}$

$\Pi_{\mathrm{b}}$ : Bank's profit after the sales season

\subsection{Retailer's Decision}

Before the sales season (time 0), the retailer has initial capital $C_{0}$ and makes $Q$ amount of order at the unit cost $c$ from the supplier before knowing the actual demand in the sales season (time $T$ ). In this study, the retailer can use a quick response strategy which is a contract with the supplier. By the quick response strategy, the retailer has two ordering opportunities. She can make the second order and moreover expedite the procuring process of the product at the higher cost from the supplier during the sales season if the demand is higher than the initial order quantity which was made before the sales season. So, the cash flow $C F_{0}$ at time 0 is given by

$$
C F_{0}=C_{0}+\left[c Q-C_{0}\right]^{+}-c Q=C_{0}+L-c Q
$$

Logically, either $C F_{0}=0$ or $L=\left[c Q-C_{0}\right]^{+}=0$ should be feasible. This comes from the following reasoning. The retailer would borrow the money up to $c Q-C_{0}$, only if $c Q-C_{0}>0$ which means that the retailer is financially insufficient for the initial ordering. Otherwise, she would not borrow the money from the bank. We assume that the retailer can make the second order to 
the supplier during the sales season. That is, if the demand occurs more than the initial ordering quantity during the sales season, the retailer would place the second order to the supplier at the higher cost, $c^{\prime}>c$, and the supplier can expedite the ordering process which can provide the products through the second order to the retailer during the sales season with a short lead time, which is called as the quick response. The second order quantity through the quick response is given by $[D-Q]^{+}$, which can be obtained since the retailer assumes to measure the exact amount of demand just after the sales season. For this, we assume that, in usual practice, most retailer experience that a popular product in the beginning of the sales season almost always turns out to be a popular product in the rest of the sales season and moreover can fairly perfectly predict sales in the rest of the sales season (Cachon \& Terwiesch, 2008). Now, the cash flow $C F_{T}$ at time $T$ is given by

$$
C F_{T}=C F_{0}+p D+s[Q-D]^{+}-c^{\prime}[D-Q]^{+}-L(1+r)
$$

Now, the following result provides the sufficient conditions in which the retailer might be bankrupt or not.

Lemma 1. Suppose that the retailer borrows positive amount of money from the bank with interest rate $r$. Then,

1. The probability for the retailer to be bankruptcy is zero when the retailer's first ordering quantity is less than $\frac{c_{0}(1+r)}{c(1+r)-s}$.

2. The probability for the retailer to be bankruptcy is strictly larger than zero when the demand is less than $\frac{[c(1+r)-s] Q+C_{0}(1+r)}{p-s}$

Proof. For the first result, for no bankruptcy risk, the cash flow after the sales season even with zero demand should be positive as follows,

$$
C F_{T}=0+p 0+s[Q-0]^{+}-c^{\prime}[0-Q]^{+}-L(1+r)=s Q-\left(c Q-C_{0}\right)(1+r)=-(c(1+r)-s) Q+C_{0}(1+r) \geq 0
$$

Thus, we have

$$
Q \leq \frac{C_{0}(1+r)}{c(1+r)-s}
$$

For the second result, first let's consider the case for $D \geq Q$. The cash flow after the sales season should be

$$
C F_{T}=0+p D-c^{\prime}[D-Q]-L(1+r) \geq p Q-c^{\prime}[D-Q]-L(1+r) \geq 0,
$$

which holds since the retailer will order $Q$ such that at least bankruptcy never happen. Now, let's consider the case for $D \leq Q$. The cash flow after the sales season will be

$$
C F_{T}=0+p D+s[Q-D]-L(1+r) .
$$

For the retailer to be bankrupt with positive probability, the cash flow after the sales season $(T)$ should be

$$
C F_{T}=0+p D+s[Q-D]-L(1+r)<0 .
$$

Thus, we have

$$
D<\frac{L(1+r)-s Q}{p-s}=\frac{\left(c Q-C_{0}\right)(1+r)-s Q}{p-s}=\frac{[c(1+r)-s] Q-C_{0}(1+r)}{p-s}
$$

So, the result holds.

Using the result of Lemma 1, the retailer's cash flow after the sales season $(T)$ is given by

$$
C F_{T}= \begin{cases}p D-c^{\prime}(D-Q)-L(1+r), & \text { if } Q \leq D \\ p D+s(Q-D)-L(1+r), & \text { if } \frac{(c(1+r)-s) Q-C_{0}(1+r)}{p-s} \leq D \leq Q \\ 0 \quad, & \text { if } D \leq \frac{(c(1+r)-s) Q-C_{0}(1+r)}{p-s}\end{cases}
$$

and moreover, the retailer's expected cash flow can be written as follows, 


$$
E\left[C F_{T}\right]=\left\{\begin{array}{lr}
(p-s) \int_{0}^{Q} D d F(D)+\left(p-c^{\prime}\right) \int_{Q}^{\infty} D d F(D)+C_{0}-\left(c-s F(Q)-c^{\prime} \bar{F}(Q)\right) Q, & \text { if } Q<\frac{C_{0}}{c} \\
(p-s) \int_{0}^{Q} D d F(D)+\left(p-c^{\prime}\right) \int_{Q}^{\infty} D d F(D)+C_{0}(1+r)-\left(c(1+r)-s F(Q)-c^{\prime} \bar{F}(Q)\right) Q, & \text { if } \frac{C_{0}}{c}<Q \leq \bar{Q} \\
(p-s) \int_{\bar{D}}^{Q} D d F(D)+\left(p-c^{\prime}\right) \int_{Q}^{\infty} D d F(D)-\left(c Q-C_{0}\right)(1+r) \bar{F}(\bar{D})+\left(s(F(Q)-F(\bar{D}))+c^{\prime} \bar{F}(Q)\right) Q, & \text { if } \bar{Q}<Q
\end{array}\right.
$$

, where $\bar{Q}=\frac{C_{0}(1+r)}{c(1+r)-s}$ and $\bar{D}=\frac{(c(1+r)-s) Q-C_{0}(1+r)}{p-s}$.

The following result provides the retailer's optimal ordering quantity given the bank's interest rate $r$ and the retailer's initial capital $C_{0}$.

Proposition 1. Suppose that the demand distribution is increasing failure rate. Given the retailer's initial cash level $C_{0}$ and the bank's interest rate $r$, the retailer's initial optimal ordering quantity $Q_{q r}^{*}$ is given by

where $\bar{Q}^{*}$ is such that

$$
Q_{q r}^{*}=\left\{\begin{aligned}
\bar{F}^{-1}\left(\frac{c-s}{c^{\prime}-s}\right), & \text { if } \bar{F}^{-1}\left(\frac{c-s}{c^{\prime}-s}\right)<\frac{C_{0}}{c} \\
\bar{F}^{-1}\left(\frac{c(1+r)-s}{c^{\prime}-s}\right), & \text { if } \frac{C_{0}}{c}<\bar{F}^{-1}\left(\frac{c-s}{c^{\prime}-s}\right)<\bar{Q} \\
\bar{Q}^{*}, & \text { if } \bar{Q}<\bar{Q}^{*}
\end{aligned}\right.
$$

$$
\bar{F}\left(\bar{Q}^{*}\right)=\frac{c(1+r)-s}{c^{\prime}-s} \bar{F}\left(\frac{(c(1+r)-s) \bar{Q}^{*}-C_{0}(1+r)}{p-s}\right)
$$

Proof. First, consider the order quantity which can be $Q<\frac{C_{0}}{c}$. Then, the first order optimality condition is as follows:

$\frac{\partial E\left[C F_{T}\right]}{\partial Q}=(p-s)[Q f(Q)]-\left(p-c^{\prime}\right) Q f(Q)-\left(c-s F(Q)-c^{\prime} \bar{F}(Q)\right)-\left(-s f(Q)+c^{\prime} f(Q)\right) Q=-c+s F(Q)+c^{\prime} \bar{F}(Q)$ $=0$

Now, we have

$$
\bar{F}(Q)=\frac{c-s}{c^{\prime}-s}
$$

Second, consider the order quantity which can be $\frac{C_{0}}{c}<Q \leq \bar{Q}$. Again, the first order optimality condition is as follows:

$$
\begin{gathered}
\frac{\partial E\left[C F_{T}\right]}{\partial Q}=(p-s)[Q f(Q)]-\left(p-c^{\prime}\right) Q f(Q)-\left(c(1+r)-s F(Q)-c^{\prime} \bar{F}(Q)\right)-\left(-s f(Q)+c^{\prime} f(Q)\right) Q \\
=-c(1+r)+s F(Q)+c^{\prime} \bar{F}(Q)=0
\end{gathered}
$$

So, we have

$$
\bar{F}(Q)=\frac{c(1+r)-s}{c^{\prime}-s}
$$

Third, consider the order quantity which can be $\bar{Q}<Q$. Again, the first order optimality condition is as follows:

$$
\begin{aligned}
\frac{\partial E\left[C F_{T}\right]}{\partial Q}=(p-s) & {\left[Q f(Q)-\frac{c(1+r)-s}{p-s} \bar{D} f(\bar{D})\right]-\left(p-c^{\prime}\right) Q f(Q)+\left(c Q-C_{0}\right)(1+r) \frac{c(1+r)-s}{p-s} f(\bar{D}) } \\
& -c(1+r) \bar{F}(\bar{D})+\left(s\left(f(Q)-\frac{c(1+r)-s}{p-s} f(\bar{D})\right)-c^{\prime} f(Q)\right) Q+\left(s(F(Q)-F(\bar{D}))+c^{\prime} \bar{F}(Q)\right) \\
& =-c(1+r) \bar{F}(\bar{D})+s \bar{F}(\bar{D})+\left(c^{\prime}-s\right) \bar{F}(Q)=-(c(1+r)-s) \bar{F}(\bar{D})+\left(c^{\prime}-s\right) \bar{F}(Q) \\
& =\left(c^{\prime}-s\right)\left[\bar{F}(Q)-\frac{c(1+r)-s}{c^{\prime}-s} \bar{F}(\bar{D})\right]
\end{aligned}
$$

So, we have

$$
\bar{F}(Q)=\frac{c(1+r)-s}{c^{\prime}-s} \bar{F}(\bar{D})
$$

Q.E.D 
Since the retailer with the quick response strategy has a second ordering chance during sales season, she would make less initial order than without the quick response strategy. This can be shown in the following Lemma.

Lemma 2. Suppose that the retailer is financially constrained and thus borrows money from the bank. Then, the retailer's initial ordering quantity with the quick response strategy is less than without the quick response strategy.

Proof. The optimal ordering quantity $Q_{q r}$ with the quick response strategy is the one such that

$$
\left(c^{\prime}-s\right) \bar{F}(Q)-(c(1+r)-s) \bar{F}\left(\frac{(c(1+r)-s) Q-C_{0}(1+r)}{p-s}\right)=0 .
$$

The optimal ordering quantity $Q_{n r}$ without the quick response strategy is the one such that

$$
(p-s) \bar{F}(Q)-(c(1+r)-s) \bar{F}\left(\frac{(c(1+r)-s) Q-C_{0}(1+r)}{p-s}\right)=0 .
$$

Now, due to $p>c^{\prime}$, the following inequality holds

$$
(p-s) \bar{F}(Q)-(c(1+r)-s) \bar{F}\left(\frac{(c(1+r)-s) Q-C_{0}(1+r)}{p-s}\right) \geq\left(c^{\prime}-s\right) \bar{F}(Q)-(c(1+r)-s) \bar{F}\left(\frac{(c(1+r)-s) Q-C_{0}(1+r)}{p-s}\right)
$$

for all $Q \geq 0$. So, the optimal ordering quantity $Q_{q r}$ with the quick response strategy is less than the optimal ordering quantity $Q_{n r}$ without the quick response strategy.

\section{Q.E.D}

As the retailer's initial capital increases, the retailer tries to lower an overstocking risk and borrow less money from the bank by lowering initial order quantity. Thus, the second ordering quantity through the quick response contract with the supplier tends to increase. This can be explained in the following Lemma 3.

Lemma 3. Suppose that the retailer is financially constrained and thus borrows money from the bank. Then, as the retailer's initial capital increases, the retailer's second ordering quantity increases almost surely.

Proof. we need to show that $\frac{\partial Q}{\partial C_{0}}$ is negative, which can be obtained by applying the implicit function theory to $\bar{F}(Q)=$ $\frac{c(1+r)-s}{c^{\prime}-s} \bar{F}(\bar{D})$ as follows,

$$
-\mathrm{f}(\mathrm{Q}) \frac{\partial Q}{\partial C_{0}}=-\frac{c(1+r)-s}{c^{\prime}-s} f(\bar{D}) \frac{(c(1+r)-s) \frac{\partial Q}{\partial C_{0}}+(1+r)}{p-s}
$$

, which can be rewritten as follows

$$
\begin{gathered}
\frac{\partial Q}{\partial C_{0}}=\frac{\frac{c(1+r)-s}{c^{\prime}-s} \frac{1+r}{p-s} f(\bar{D})}{-\mathrm{f}(\mathrm{Q})+\frac{c(1+r)-s}{c^{\prime}-s} \frac{(c(1+r)-s)}{p-s} f(\bar{D})}=\frac{\frac{c(1+r)-s}{c^{\prime}-s} \frac{1+r}{p-s} \frac{f(\overline{\bar{D}})}{\bar{F}(\bar{D})}}{-\frac{\bar{F}(Q)}{\bar{F}(\bar{D})} \frac{f(\mathrm{Q})}{\bar{F}(Q)}+\frac{c(1+r)-s}{c^{\prime}-s} \frac{(c(1+r)-s)}{p-s} \frac{f(\bar{D})}{\bar{F}(\bar{D})}}=\frac{\frac{c(1+r)-s}{c^{\prime}-s} \frac{1+r}{p-s} z(\bar{D})}{-\frac{c(1+r)-s}{c^{\prime}-s} z(\mathrm{Q})+\frac{c(1+r)-s}{c^{\prime}-s} \frac{(c(1+r)-s)}{p-s} z(\bar{D})}=\frac{\frac{1+r}{p-s} z(\bar{D})}{-z(\mathrm{Q})+\frac{(c(1+r)-s)}{p-s} z(\bar{D})} \\
=\frac{\frac{1+r}{p-s} z(\bar{D})}{\frac{(c(1+r)-s)}{p-s} z(\bar{D})-z(\mathrm{Q})}<0
\end{gathered}
$$

where the third equality holds due to $\bar{F}(Q)=\frac{c(1+r)-s}{c^{\prime}-s} \bar{F}(\bar{D})$ and the last inequality holds due to $\left(\frac{c(1+r)-s}{p-s}\right) z(\bar{D})-z(Q)<0$ since the demand distribution function in increasing failure rate. Now, the retailer's second ordering quantity for every demand outcome $D$ is given by $[D-Q]^{+}$. Since we show that the retailer's initial ordering quantity decreases as the retailer's initial capital increases, for every demand outcome, $[D-Q]^{+}$increases almost surely.

Q.E.D

Since the retailer with the quick response strategy has a second ordering chance during sales season, she can generate more profit than without the quick response strategy by grapping the demand which might be lost due to the lack of the initial order but can be captured by the second order at the higher unit cost. Moreover, from Lemma 3, we can see that if the retailer is wealthy with higher initial capital, she might focus more on the second order than on the initial order since she can remove the salvage cost and increase the customer's satisfaction.

\subsection{Bank's Decision}

We consider a monopolistic capital market based on the liberalization of interest rate. This implies that the bank can maximize the expected profit by setting a proper interest rate. So, given the retailer's optimal decision $Q$, the bank's profit after the sales season $(T)$ can be written using the result of Lemma 1 , 


$$
\Pi_{b}=\left\{\begin{aligned}
& \text { J. Lee /Accounting } 6 \text { (2020) } \\
& p D+s(Q-D)-\left(c Q-C_{0}\right), \text { if } D \leq \frac{[c(1+r)-s] Q+C_{0}(1+r)}{p-s} \\
&\left(c Q-C_{0}\right) r, \text { f } D \geq \frac{[c(1+r)-s] Q+C_{0}(1+r)}{p-s}
\end{aligned}\right.
$$

Then, the bank's objective is as follows

$$
\max _{r \geq 0} E\left[\Pi_{b}\right]
$$

where $E\left[u\left(\Pi_{b}\right)\right]$ is the bank's expected profit at time 0 given by

$$
\int_{0}^{\frac{(c(1+r)-s) Q-C_{0}(1+r)}{p-s}}\left(p D+s(Q-D)-\left(c Q-C_{0}\right)\right) d F(D)+\int_{\frac{(c(1+r)-s) Q-C_{0}(1+r)}{p-s}}^{\infty}\left(c Q-C_{0}\right) r d F(D)
$$

In the following result, we show that there exists an optimal interest rate for bank which can offer to the retailer and that the retailer's order quantity is a decreasing function in the bank's interest rate.

Proposition 2. Suppose that the demand distribution is increasing failure rate. Then

1. The bank's optimal interest rate is a value $r^{*}$ satisfying the following equations

$$
\begin{gathered}
\left(-(c-s)+\left(c\left(1+r^{*}\right)-s\right) \bar{F}(\bar{D})\right) \frac{\partial Q}{\partial r}+\left(c Q-C_{0}\right) \bar{F}(\bar{D})=0 \\
\frac{\partial Q}{\partial r}=\frac{c \bar{F}(\bar{D})-(c(1+r)-s) \frac{c Q-C_{0}}{p-s} f(\bar{D})}{\frac{(c(1+r)-s)^{2}}{p-s} f(\bar{D})-\left(c^{\prime}-s\right) \mathrm{f}(Q)}
\end{gathered}
$$

2. As the interest rate increases, the retailer's initial ordering quantity decreases.

Proof. Letting $\bar{D}=\frac{(c(1+r)-s) Q-C_{0}(1+r)}{p-s}$, the bank's expected profit can be written as follows

$$
\begin{gathered}
E\left[\Pi_{b}\right]=\int_{0}^{\bar{D}}\left(p D+s(Q-D)-\left(c Q-C_{0}\right)\right) d F(D)+\int_{\bar{D}}^{\infty}\left(c Q-C_{0}\right) r d F(D)=\int_{0}^{\bar{D}}\left((p-s) D-\left(c Q-C_{0}\right)+s Q+\left(c Q-C_{0}\right) r-\left(c Q-C_{0}\right) r\right) d F(D)+\int_{\bar{D}}^{\infty}\left(c Q-C_{0}\right) r d F(D) \\
=-(p-s) \int_{0}^{\bar{D}}\left(-D+\frac{(c(1+r)-s) Q-C_{0}(1+r)}{p-s}\right) d F(D)+\int_{0}^{\bar{D}}\left(c Q-C_{0}\right) r d F(D)+\int_{\bar{D}}^{\infty}\left(c Q-C_{0}\right) r d F(D) \\
=-(p-s) \int_{0}^{\bar{D}}(\bar{D}-D) d F(D)+\left(c Q-C_{0}\right) r
\end{gathered}
$$

The first-order derivative optimality condition for bank's expected profit is given by

$$
\begin{aligned}
\frac{\partial E\left[\Pi_{b}\right]}{\partial r}=c \frac{\partial Q}{\partial r} r+ & \left(c Q-C_{0}\right)-(p-s) \int_{0}^{\bar{D}} \frac{(c(1+r)-s) \frac{\partial Q}{\partial r}+c Q-C_{0}}{p-s} d F(D) \\
& =c r \frac{\partial Q}{\partial r}+\left(c Q-C_{0}\right)-\int_{0}^{\bar{D}}\left[(c(1+r)-s) \frac{\partial Q}{\partial r}+c Q-C_{0}\right] d F(D) \\
& =(c r-(c(1+r)-s) F(\bar{D})) \frac{\partial Q}{\partial r}+\left(c Q-C_{0}\right) \bar{F}(\bar{D}) \\
& =(c r-(c(1+r)-s)+(c(1+r)-s)-(c(1+r)-s) F(\bar{D})) \frac{\partial Q}{\partial r}+\left(c Q-C_{0}\right) \bar{F}(\bar{D}) \\
& =(-(c-s)+(c(1+r)-s) \bar{F}(\bar{D})) \frac{\partial Q}{\partial r}+\left(c Q-C_{0}\right) \bar{F}(\bar{D})
\end{aligned}
$$

Since $Q_{n q} \geq Q_{q r}$ from Lemma 2 and thus $\frac{c-s}{c^{\prime}-s}=\bar{F}\left(Q_{n q}\right)<\bar{F}\left(Q_{q r}\right)=\frac{c(1+r)-s}{c^{\prime}-s} \bar{F}(\bar{D})$, we have $-(c-s)+(c(1+r)-$ $s) \bar{F}(\bar{D})>0$. So. With $\left(c Q-C_{0}\right) \bar{F}(\bar{D})$, we have $\frac{\partial Q}{\partial r}<0$. This implies that, as the interest increases, the retailer's ordering quantity decreases. Now, we need to find $\frac{\partial Q}{\partial r}$, which can be obtained by applying the implicit function theory to $\bar{F}(Q)=$ $\frac{c(1+r)-s}{c^{\prime}-s} \bar{F}(\bar{D})$ as follows,

$$
-\mathrm{f}(\mathrm{Q}) \frac{\partial Q}{\partial r}=\frac{c}{c^{\prime}-s} \bar{F}(\bar{D})-\frac{c(1+r)-s}{c^{\prime}-s} f(\bar{D}) \frac{(c(1+r)-s) \frac{\partial Q}{\partial r}+c Q-C_{0}}{p-s}
$$

which can be rewritten as follows

$$
\left[-\mathrm{f}(\mathrm{Q})+\frac{c(1+r)-s}{c^{\prime}-s} f(\bar{D}) \frac{(c(1+r)-s)}{p-s}\right] \frac{\partial Q}{\partial r}=\frac{c}{c^{\prime}-s} \bar{F}(\bar{D})-\frac{c(1+r)-s}{c^{\prime}-s} \frac{c Q-C_{0}}{p-s} f(\bar{D})
$$


Then, the retailer's response to the bank's interest rate is given by

Then, the result holds.

$$
\frac{\partial Q}{\partial r}=\frac{\frac{c}{c^{\prime}-s} \bar{F}(\bar{D})-\frac{c(1+r)-s}{c^{\prime}-s} \frac{c Q-C_{0}}{p-s} f(\bar{D})}{\frac{c(1+r)-s}{c^{\prime}-s} f(\bar{D}) \frac{(c(1+r)-s)}{p-s}-f(Q)}=\frac{c \bar{F}(\bar{D})-(c(1+r)-s) \frac{c Q-C_{0}}{p-s} f(\bar{D})}{\frac{(c(1+r)-s)^{2}}{p-s} f(\bar{D})-\left(c^{\prime}-s\right) f(Q)}
$$

Q.E.D

Intuitively, the retailer would increase the initial ordering quantity if the unit cost through the quick response is higher. Also, the higher the retailer's initial order quantity is, the more money she would borrow from the bank. This intuition is explained in the following Lemma.

Lemma 4. Suppose that the demand distribution function has an increasing failure rate (IFR). Then, given $C_{0}$, as $c^{\prime}$ increases, the initial ordering quantity increases and the amount of loan from the bank increases.

Proof. From Proposition 1, applying the implicit function theory to $\bar{F}(Q)=\frac{c(1+r)-s}{c^{\prime}-s} \bar{F}(\bar{D})$,

$$
\begin{gathered}
-\mathrm{f}(\mathrm{Q}) \frac{\partial Q}{\partial c^{\prime}}=-\frac{c(1+r)-s}{\left(c^{\prime}-s\right)^{2}} \bar{F}(\bar{D})-\frac{c(1+r)-s}{c^{\prime}-s} f(\bar{D}) \frac{(c(1+r)-s) \frac{\partial Q}{\partial c^{\prime}}}{p-s} \\
\frac{\partial Q}{\partial c^{\prime}}=-\frac{\frac{c(1+r)-s}{\left(c^{\prime}-s\right)^{2}} \bar{F}(\bar{D})}{\frac{(c(1+r)-s)^{2}}{\left(c^{\prime}-s\right)(p-s)} f(\bar{D})-f(\mathrm{Q})}=-\frac{\frac{1}{c^{\prime}-s}}{\frac{c(1+r)-s}{p-s} \frac{f(\bar{D})}{\bar{F}(\bar{D})}-\frac{c^{\prime}-s}{c(1+r)-s} \overline{\bar{F}(Q)} \overline{\bar{F}(\bar{D})} \frac{f(\mathrm{Q})}{\bar{F}(Q)}}=-\frac{\frac{1}{c^{\prime}-s}}{\frac{c^{\prime}-s}{c(1+r)-s} z(\bar{D})-\frac{c(1+r)-s}{c(1+r)-s} \frac{\left.c^{\prime}-s\right)}{c^{\prime}-s} z(\mathrm{Q})} \\
=-\frac{\frac{1}{c^{\prime}-s}}{\frac{c(1+r)-s}{p-s} z(\bar{D})-z(\mathrm{Q})}>0
\end{gathered}
$$

where the last inequality holds due to $-z(Q)+\left(\frac{c(1+r)-s}{p-s}\right) z(\bar{D})<0$. So, as $c^{\prime}$ increases, the first ordering quantity increases and thus the amount of loan from the bank, which is $c Q-C_{0}$, should also increase. The result holds.

Q.E.D

If the retailer's initial capital is higher, then the money she would borrow from the bank would decrease. This implies that the demand for the money market decreases, the value of money decreases and thus the bank would provide the lower interest rate to the retailer. This intuition can be explained in the following Lemma.

Lemma 5. Suppose that the demand distribution function has an increasing failure rate (IFR). Then, as $C_{0}$ increases, the interest rate decreases.

Proof. From Proposition 1, applying the implicit function theory to $\bar{F}(Q)=\frac{c(1+r)-s}{c^{\prime}-s} \bar{F}(\bar{D})$, we have

$$
\begin{aligned}
& -\mathrm{f}(\mathrm{Q}) \frac{\partial Q}{\partial C_{0}}=-\frac{c \frac{\partial r}{\partial c_{0}}}{\left(c^{\prime}-s\right)^{2}} \bar{F}(\bar{D})-\frac{c(1+r)-s}{c^{\prime}-s} f(\bar{D}) \frac{(c(1+r)-s) \frac{\partial Q}{\partial c_{0}}+c \frac{\partial r}{\partial c_{0}} Q-(1+r)-C_{0} \frac{\partial r}{\partial c_{0}}}{p-s} \\
& \frac{\partial r}{\partial C_{0}}=\frac{\mathrm{f}(\mathrm{Q})-\frac{c(1+r)-s}{c^{\prime}-s} \frac{(c(1+r)-s)}{p-s} f(\bar{D})}{\frac{c}{\left(c^{\prime}-s\right)^{2}} \bar{F}(\bar{D})+\frac{c(1+r)-s}{c^{\prime}-s} \frac{c Q-(1+r)-C_{0}}{p-s} f(\bar{D})} \frac{\partial Q}{\partial C_{0}}=\frac{\frac{\bar{F}(Q)}{\bar{F}(\bar{D})} \frac{f(\mathrm{Q})}{\bar{F}(Q)}-\frac{c(1+r)-s}{c^{\prime}-s} \frac{(c(1+r)-s)}{p-s} \frac{f(\bar{D})}{\bar{F}(\bar{D})}}{\frac{c Q}{\left(c^{\prime}-s\right)^{2}}+\frac{c(1+r)-s}{c^{\prime}-s} \frac{c Q-(1+r)-C_{0}}{p(\bar{D})}} \frac{\partial Q}{\bar{F}(\bar{D})} \frac{\partial C_{0}}{p-s} \\
& =\frac{\frac{c(1+r)-s}{c^{\prime}-s} z(Q)-\frac{c(1+r)-s}{c^{\prime}-s} \frac{(c(1+r)-s)}{p-s} z(\bar{D})}{\frac{c}{\left(c^{\prime}-s\right)^{2}}+\frac{c(1+r)-s}{c^{\prime}-s} \frac{c Q-(1+r)-C_{0}}{p-s} \frac{f(\bar{D})}{\bar{F}(\bar{D})}} \frac{\partial Q}{\partial C_{0}}=\frac{z(Q)-\frac{(c(1+r)-s)}{p-s} z(\bar{D})}{\frac{c}{c^{\prime}-s} \frac{1}{c Q-(1+r)-C_{0}}+\frac{c Q-(1+r)-C_{0}}{p-s} z(\bar{D})} \frac{\partial Q}{\partial C_{0}}<0
\end{aligned}
$$

where the last inequality holds due to $z(Q)-\left(\frac{c(1+r)-s}{p-s}\right) z(\bar{D})>0$ and $\frac{\partial Q}{\partial c_{0}}<0$ from Lemma 3.

So, as $C_{0}$ increases, the interest rate decreases. The result holds.

Q.E.D

\section{Numerical Results}

In this section, we provide a numerical example to see how the model parameters affect the optimal solution for the retailer and the bank. We consider the following simple example of a supplier and bank. Let $p=1, c=0.4, c^{\prime}=0.6, s=0$ and the demand is exponentially distributed with mean 100 . 


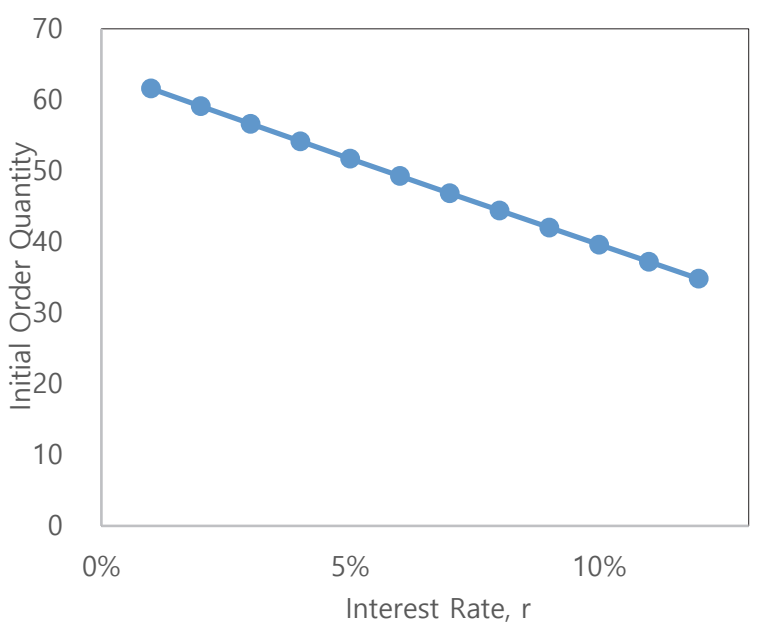

Fig. 1. Bank's Interest Rate Vs. Retailer's Optimal Initial Order Quantity

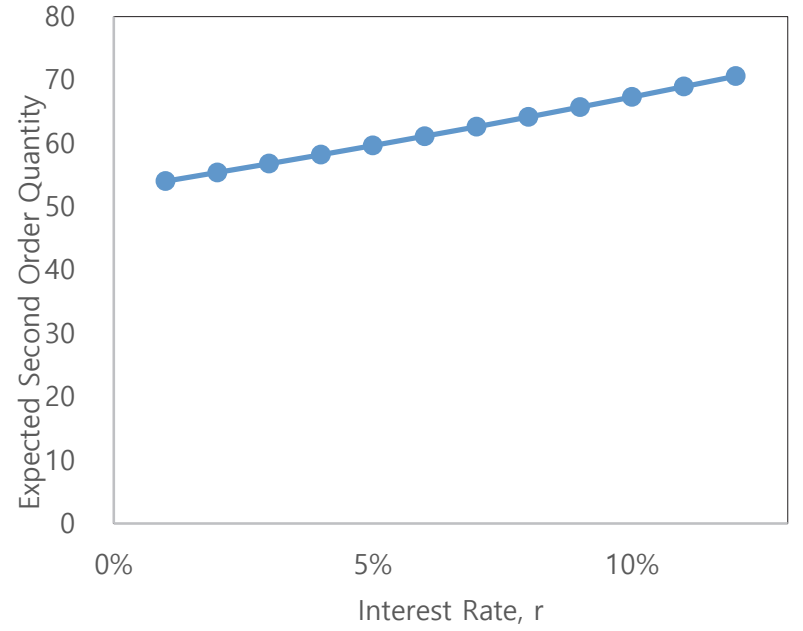

Fig. 2. Bank's Interest Rate Vs. Retailer's Expected Second Order Quantity

Fig. 1 shows the effect of the bank's interest rate on the retailer's optimal initial order quantity. As shown in Proposition 2, as the bank's interest rate increases, the retailer's optimal initial order quantity decreases.

Fig. 2 shows the effect of the bank's interest rate on the retailer's expected second order quantity. As shown in Lemma 3, as the bank's interest rate increases, the retailer's s expected second order quantity increases.

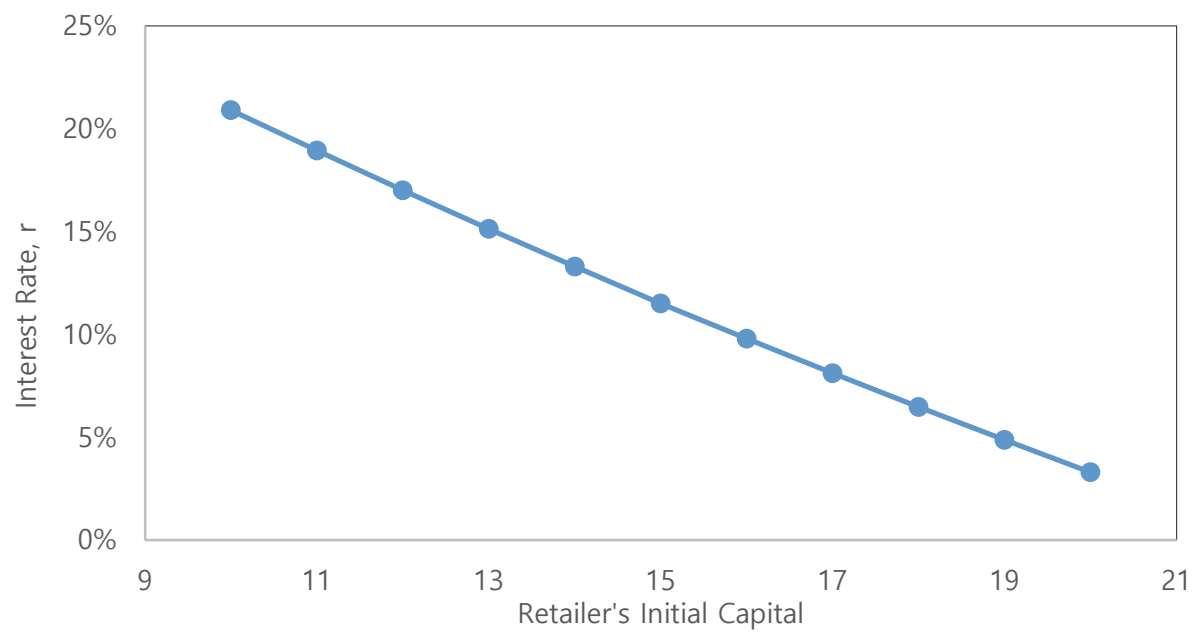

Fig. 3 Bank’s Optimal Interest Rate vs. Bank’s Coefficient of Loss-aversion

Fig. 3 shows the effect of the retailer's initial capital on the bank's optimal interest rate. As shown in Lemma 4, as the retailer's initial capital increases, the bank's optimal interest rate decreases.

\section{Conclusion}

In this study, we have analysed financially constrained supply chain which consists of a financially-deficient retailer and a bank. The bank provides loan to the retailer. And, we assume that the retailer makes a quick response contract with the supplier. Although there have been studies on financially constrained supply chain problems, there has been no study on the financially constrained retailer's quick response strategy. With this quick response contract between the supplier and the retailer in the financially constrained supply chain, we derived the optimal decision for the retailer and bank. Then, we conducted a sensitivity analysis to see how the parameters in our model affect each player's optimal decision. Through analytical and numerical analysis, the following results are obtained: First, in the financially constrained supply chain with bank credit, we see the effect of the bank's decision on the retailer's optimal decision. The retailer's optimal initial ordering decision is a non-increasing 
function of the bank's decision, interest rate. These upstream player's decision in the supply chain can be used as a method to adjust the retailer's potential default risk. Second, in the financially constrained supply chain with bank's lending, as the procuring cost by the quick response increases, the retailer's initial ordering quantity increases and thus the amount of loan from the bank increases. Intuitively, the retailer would increase the initial ordering quantity if the unit cost through the quick response is higher. Also, the higher the retailer's initial order quantity is, the more money she would borrow from the bank. Third, in the financially constrained supply chain, as the retailer's initial capital increases, the bank's interest rate decreases. If the retailer's initial capital is higher, then the money she would borrow from the bank would decrease. This implies that the demand for the money market decreases, the value of money decreases and thus the bank would provide the lower interest rate to the retailer. Forth, in the financially constrained supply chain, the retailer's initial ordering quantity with the quick response strategy is less than without the quick response strategy. Moreover, this result with the third result above, we can find that as the retailer's initial capital increases, the retailer's second ordering quantity increases almost surely.

This study contributes to the area of financially constrained supply chain model by integrating bank credit with the quick response contract between the retailer and the supplier to see the effect of bank credit and the quick response on each player's optimal decision. Also, we see how the optimal decisions and quick response strategy in the supply chain influence the optimal decision by ignoring the goodwill loss cost, salvage cost, quantity discounts and the buyback policy, which are the limitation of this study. So, in the future study, we can extend our study to the model (1) with quantity discount or the buyback policy and (2) with the risk-averse or risk-seeking or overconfident behavior.

\section{Acknowledgement}

This work was supported by 2019 Hongik University Research Fund.

\section{References}

Buzacott, J. A., \& Zhang, R. Q. (2004). Inventory management with asset-based financing. Management Science, 50(9), 12741292.

Cachon, G., \& Terwiesch, C. (2008). Matching supply with demand. McGraw-Hill Publishing.

Cachon, G. P., \& Swinney, R. (2009). Purchasing, pricing, and quick response in the presence of strategic consumers. Management Science, 55(3), 497-511.

Cachon, G. P., \& Swinney, R. (2011). The value of fast fashion: Quick response, enhanced design, and strategic consumer behavior. Management science, 57(4), 778-795.

Camerer, C. F. (1988). Taking risks: The management of uncertainty. Administrative Science Quarterly, 33(4), 638-640.

Dada, M., \& Hu, Q. (2008). Financing newsvendor inventory. Operations Research Letters, 36(5), $569-573$.

Iyer, A. V., \& Bergen, M. E. (1997). Quick response in manufacturer-retailer channels. Management science, 43(4), 559-570.

Jing, B., Chen, X., \& Cai, G. (2012). Equilibrium financing in a distribution channel with capital constraint. Production and Operations Management, 21(6), 1090-1101.

Kahneman, D., \& Tversky, A. (2013). Prospect theory: An analysis of decision under risk. In Handbook of the fundamentals of financial decision making: Part I (pp. 99-127).

Kouvelis, P., \& Zhao, W. (2012). Financing the newsvendor: supplier vs. bank, and the structure of optimal trade credit contracts. Operations Research, 60(3), 566-580.

Kouvelis, P., \& Zhao, W. (2016). Supply chain contract design under financial constraints and bankruptcy costs. Management Science, 62(8), 2341-2357.

Lee, C. H., \& Rhee, B. D. (2011). Trade credit for supply chain coordination. European Journal of Operational Research, 214(1), 136-146.

Suri, R. (1998). Quick response manufacturing: a companywide approach to reducing lead times. Productivity Press.

Xu, X., \& Birge, J. R. (2004). Joint production and financing decisions: Modeling and analysis. Available at SSRN 652562.

Yang, S. A., \& Birge, J. R. (2018). Trade credit, risk sharing, and inventory financing portfolios. Management Science, 64(8), 3667-3689.

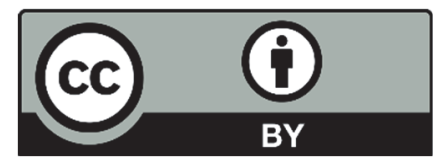

(C) 2020 by the authors; licensee Growing Science, Canada. This is an open access article distributed under the terms and conditions of the Creative Commons Attribution (CC-BY) license (http://creativecommons.org/licenses/by/4.0/). 